\title{
TIMI risk score for secondary prevention of recurrent cardiovascular events in a real-world cohort of post- non-ST-elevation myocardial infarction patients
}

\author{
Duo Huang, ${ }^{1}$ Yang Yang Cheng, ${ }^{1}$ Yiu Tung Wong, ${ }^{1}$ See Yue Yung, ${ }^{1}$ Ki Wan Chan, \\ Cheung Chi Lam, ${ }^{1}$ JoJo Hai, ${ }^{1}$ Chu Pak Lau ${ }^{1}{ }^{1}$ Ka Lam Wong, ${ }^{1}$ Ying Qing Feng, ${ }^{2}$ \\ Ning Tan, ${ }^{2} \mathrm{Ji}$ Yan Chen, ${ }^{2}$ Ming Xiang Wu, ${ }^{3} \mathrm{Xi} \mathrm{Su},{ }_{1}{ }^{3}$ Hua Yan, ${ }^{3}$ Dan Song, ${ }^{3}$ Hung Fat Tse, \\ Pak Hei Chan, ${ }^{1}$ Chung Wah Siu, ${ }^{1}$ Chor Cheung Tam ${ }^{01}$
}

\begin{abstract}
${ }^{1}$ Medicine, The University of Hong Kong, Hong Kong, China ${ }^{2}$ Department of Cardiology, Guangdong Cardiovascular Institute, GuangZhou, China ${ }^{3}$ Wuhan Asian Heart Hospital, Wuhan, China
\end{abstract}

\section{Correspondence to} Dr Chor Cheung Tam, and Dr Chung Wah Siu, Medicine, The University of Hong Kong, Hong Kong, China;

frankie.tamcc@gmail.com, cwdsiu@hku.hk

Received 9 January 2019 Revised 10 April 2019 Accepted 25 April 2019 Published Online First 23 May 2019

Check for updates

(C) Author(s) (or their employer(s)) 2019. No commercial re-use. See rights and permissions. Published by BMJ.

To cite: Huang D, Cheng YY, Wong YT, et al.

Postgrad Med J

2019:95:372-377.

\section{ABSTRACT}

Background Patients who survive non-ST-elevation myocardial infarction (NSTEMI) are at heightened risk of recurrent cardiovascular events. Data on long-term secondary atherothrombotic risk stratification are limited. Objectives To stratify post-NSTEMI patients for risk of recurrent cardiovascular events to maximise benefit from aggressive secondary prevention strategies using the TIMI Risk Score for Secondary Prevention (TRS $2^{\circ} \mathrm{P}$ ) score in a real-world cohort of NSTEMI patients.

Methods and results This was a single-centre observational study of 891 post-NSTEMI patients (73.7 \pm 12.7 years; male: $54.2 \%$ ). The TRS $2^{\circ} \mathrm{P}$ is a nine-point risk stratification tool to predict cardiovascular events in patients with established cardiovascular disease. The primary outcome was a composite endpoint of cardiovascular death, non-fatal MI and non-fatal ischaemic stroke. After a median follow-up of 31 months (IQR: $11.4-60.2), 281$ patients (31.5\%) had developed a primary outcome (13.3\%/year) including 196 cardiovascular deaths, 94 non-fatal Mls and 22 non-fatal strokes. The TRS $2^{\circ} \mathrm{P}$ score was strongly associated with the primary outcome. The annual incidence of primary composite endpoint for patients with TRS $2^{\circ} \mathrm{P}$ score $=0$ was $1.6 \%$, and increased progressively to $47.4 \%$ for those with a TRS $2^{\circ} \mathrm{P}$ score $\geq 6$ (HR: $20.18,95 \% \mathrm{Cl}$ : 4.85 to $84.05, p<0.001)$. Similar associations were also observed between the TRS $2^{\circ} \mathrm{P}$ score and cardiovascular death and MI (fatal and non-fatal), but not non-fatal ischaemic stroke.

Conclusion The TRS $2^{\circ} \mathrm{P}$ score stratified post-NSTEMI patients for risk of future cardiovascular events and potentially help guide the selection of more aggressive secondary prevention therapy.

\section{INTRODUCTION}

Acute coronary syndrome (ACS) is a disease of high mortality and morbidity. ${ }^{1}$ Myocardial revascularisation and evidence-based medications have dramatically improved short-term patient outcomes. However, patients who survive ACS are at heightened risk of a future major cardiovascular (CV) event. $^{1-3}$ Clinically, ACS can be subdivided into ST-elevation myocardial infarction (STEMI), non-ST-elevation myocardial infarction (NSTEMI) and unstable angina. Traditionally, more emphasis has been put on acute reperfusion therapy for acute
STEMI. Nevertheless, it was reported that the hospitalisation burden for ACS has been increasing with a transition from STEMI to NSTEMI. ${ }^{4}$ Moreover, patients suffering from NSTEMI have a higher long-term risk of adverse CV outcomes than patients with STEMI. ${ }^{5-8}$ Therefore, aggressive secondary preventive measures such as prolonged dual antiplatelet therapy, ${ }^{9}$ potent statin therapy ${ }^{3}$ and non-statin therapy, ezetimibe, ${ }^{10}{ }^{11}$ proprotein convertase subtilisin/kexin (PCSK) type 9 inhibitors $^{12}$ are indicated to mitigate recurrent $\mathrm{CV}$ risk. However, such therapies may be accompanied by side effects such as bleeding and may also be prohibitively expensive. ${ }^{13-15}$ As a result, risk stratification to identify very high-risk patients will allow efficient use of these agents.

Recently, the Thrombolysis In Myocardial Infarction (TIMI) group has developed a TIMI Risk Score for Secondary Prevention (TRS $2^{\circ} \mathrm{P}$ ) score to predict long-term recurrent $\mathrm{CV}$ events using data from the Thrombin Receptor Antagonist in Secondary Prevention of Atherothrombotic Ischemic Events, Thrombolysis In Myocardial Infarction (TIMI) 50 trial. $^{16}{ }^{17}$ TRS $2^{\circ} \mathrm{Ps}$ score incorporates nine readily available clinical characteristics-congestive heart failure, hypertension, diabetes mellitus, age $\geq 75$ years, prior stroke, prior coronary artery bypass graft, peripheral artery disease, estimated glomerular filtration rate $(e G F R)<60 \mathrm{~mL} / \mathrm{min}$ and smoking - and is able to identify approximately fivefold gradient in the risk of recurrent major CV events across low-risk, intermediate-risk and highrisk categories. ${ }^{17}$ The score has been externally validated for prediction of recurrent CV events in ACS patients in the Improved Reduction of Outcomes: Vytorin Efficacy International Trial (IMPROVE-IT) trial. ${ }^{18}$ In this study, we would like to validate the use of TRS $2^{\circ} \mathrm{P}$ score in a large contemporary 'realworld' cohort of post-NSTEMI patients to predict long-term recurrent $\mathrm{CV}$ risks.

\section{METHODS \\ Study design and patients}

This was an observational study using a singlecentre ACS registry. ${ }^{19} 20$ Patients with diagnosis of NSTEMI based on the standard Ninth International Classification of Disease code of 410.71 at Queen Mary Hospital, Hong Kong, from February 2004 
to January 2011, were identified from the hospital computerised database. In Hong Kong, all hospital admissions, outpatient clinic visits, laboratory results and radiological images are recorded in a computer-based clinical management system since 1996. Hospital records of the index NSTEMI were reviewed to confirm the authenticity of the diagnosis according to the following criteria: (1) presence of chest pain $\geq 30 \mathrm{~min}$; (2) absence of STE in the admission ECG; (3) ST and T waves changes were present for at least 24 hours and (4) positive myocardial necrosis markers. Patients who died during hospitalisation for the index NSTEMI were excluded from the final analysis. Demographic data, CV risk factors and medications were recorded at baseline. The index date was defined as the date of the first occurrence of acute NSTEMI. For outcome assessment, a blanking period of 14 days after the index event was applied since the occurrence of recurrent ACS, an ischaemic stroke or CV death within the first few days of acute NSTEMI was most likely related to the initial presentation rather than a new event.

\section{TIMI Risk Score for Secondary Prevention}

The TRS $2^{\circ} \mathrm{P}$ is a simple nine-point risk stratification tool to predict CV death, MI and ischaemic stroke. ${ }^{18}$ As previously described, the TRS $2^{\circ} \mathrm{P}$ score was calculated at baseline: congestive heart failure (one point), hypertension (one point), age $\geq 75$ years (one point), diabetes mellitus (one point), prior stroke (one point), prior coronary artery bypass grafting (one point), peripheral arterial disease (one point), eGFR $<60 \mathrm{~mL} / \mathrm{min}$ (1 point) and smoking (one point). All of these are independent factors for future CV risk in post-ACS patients. Subsequent occurrence of risk factors that could contribute to the TRS $2^{\circ} \mathrm{P}$ score was not taken into account.

\section{Outcomes, variables and data source}

The primary outcome was a composite of (1) non-fatal MI, (2) non-fatal ischaemic stroke and (3) CV death. Secondary outcomes included CV death, non-fatal MI, fatal MI, non-fatal ischaemic stroke and fatal ischaemic stroke. MI was defined by a clinical scenario consistent with MI requiring hospitalisation, confirmed by the presence of either ECG evidence or cardiac marker evidence. Ischaemic stroke was defined as a neurological deficit of sudden onset, persisting for $>24$ hours, corresponding to a vascular territory and not explained by other causes (eg, trauma and infection) with neuroimaging evidence, either from CT or MRI, confirming the diagnosis. CV death was defined as death that occurred during hospitalisation for a documented MI, stroke, other non-cerebral, non-coronary vascular disease, heart failure and/or ventricular tachyarrhythmia, in which there was no conclusive evidence for another cause of death, as well as sudden cardiac death classified according to the Modified Hinkle-Thaler scheme. ${ }^{2122}$ All patients were monitored until the follow-up date in our cardiac outpatient clinic or until they died. Data were retrieved from the medical records and discharge summaries from the territory-wide information network of all public hospitals in Hong Kong. Patients who were lost to follow-up were contacted by phone. In addition, survival data were obtained from the Births and Deaths General Register Office.

\section{Statistical analysis}

Continuous and discrete variables are expressed as mean \pm standard derivation and percentages, respectively. Statistical comparison of the baseline clinical characteristics was performed using Student's t-test or one-way ANOVA as appropriate. KaplanMeier survival analyses with the log-rank test were carried
Table 1 Baseline characteristics, in-patient revascularisation and discharge medications

\begin{tabular}{|c|c|}
\hline Demographics & $(n=891)$ \\
\hline Mean age, years & $73.7 \pm 12.7$ \\
\hline Male, n (\%) & $483(54.2)$ \\
\hline Hypertension, n (\%) & $579(65)$ \\
\hline Diabetes mellitus, n (\%) & $351(39.4)$ \\
\hline Smoker, n (\%) & $375(42.1)$ \\
\hline Heart failure, $\mathrm{n}(\%)$ & $110(12.3)$ \\
\hline Peripheral arterial disease, $\mathrm{n}(\%)$ & $44(4.9)$ \\
\hline Prior coronary revascularisation, $\mathrm{n}(\%)$ & $122(13.7)$ \\
\hline Prior stroke, $\mathrm{n}(\%)$ & $168(18.9)$ \\
\hline Prior CABG, $n(\%)$ & $63(7.1)$ \\
\hline eGFR <60 mL/min, $\mathrm{n}(\%)$ & $484(54.3)$ \\
\hline Mean TRS $2^{\circ} \mathrm{P}$ score & $3.0 \pm 1.6$ \\
\hline \multicolumn{2}{|l|}{ TRS $2^{\circ} \mathrm{P}$ score } \\
\hline $0, \mathrm{n}(\%)$ & $43(4.8)$ \\
\hline $1, \mathrm{n}(\%)$ & $130(14.6)$ \\
\hline $2, \mathrm{n}(\%)$ & $179(20.1)$ \\
\hline $3, \mathrm{n}(\%)$ & $206(23.1)$ \\
\hline $4, n(\%)$ & $168(18.9)$ \\
\hline $5, \mathrm{n}(\%)$ & $106(11.9)$ \\
\hline $6-9, \mathrm{n}(\%)$ & $59(6.6)$ \\
\hline \multicolumn{2}{|c|}{ Discharge medications and in-patient revascularisation } \\
\hline Aspirin, n (\%) & $772(86.8)$ \\
\hline P2Y12 inhibitor, $n(\%)$ & $349(39.2)$ \\
\hline Warfarin, n (\%) & $33(3.7)$ \\
\hline ACEI, n (\%) & $497(55.8)$ \\
\hline Beta-blocker, n (\%) & $574(64.4)$ \\
\hline Calcium channel blocker, $\mathrm{n}(\%)$ & $211(23.7)$ \\
\hline Statin, n (\%) & $555(62.3)$ \\
\hline In-patient PCI, n (\%) & $206(23.1)$ \\
\hline In-patient CABG, n (\%) & $23(2.6)$ \\
\hline
\end{tabular}

ACEI, ACE inhibitor; CABG, coronary artery bypass grafting; eGFR, estimated glomerular filtration rate; $\mathrm{PCl}$, percutaneous coronary intervention;TRS $2^{\circ} \mathrm{P}$, Thrombolysis In Myocardial Infarction Risk Score for Secondary Prevention.

out, and Cox proportional hazards regression model was used to calculate HRs of some predictive factors and their 95\% CIs for the incidence of different outcomes. Calculations were performed using SPSS software V.21.0. All tests were two-sided, and $\mathrm{p}$ values were considered significant if $<0.05$.

\section{RESULTS}

\section{Baseline characteristics}

From February 2004 to January 2011, 891 patients hospitalised for an acute NSTEMI were included in final analysis. Table 1 summarises their clinical characteristics, in-patient revascularisation and discharge medications. The mean age was $73.7 \pm 12.7$ years with a male predominance $(54.2 \%)$. Of note, $65 \%$ of patients had hypertension, $39.4 \%$ had diabetes, $13.7 \%$ had prior coronary artery disease requiring revascularisation, $18.9 \%$ had had a previous stroke and $54.3 \%$ had an eGFR $<60 \mathrm{~mL} / \mathrm{min}$. The mean TRS $2^{\circ} \mathrm{P}$ score was $3.0 \pm 1$.6. In-patient coronary revascularisation including both percutaneous coronary intervention and coronary artery bypass grafting was performed in 229 patients (25.7\%). On discharge, most patients were prescribed aspirin (86.8\%), 39.2\% were prescribed a P2Y12 inhibitor and 3.7\% warfarin. In addition, $62.3 \%$ of patients were prescribed a statin, 
Table 2 Associations between baseline factors and composite endpoint (cardiovascular death, non-fatal myocardial infarction and non-fatal stroke)

\begin{tabular}{|c|c|c|c|c|c|}
\hline & \multirow{2}{*}{$\begin{array}{l}\text { Number of composite } \\
\text { endpoints }\end{array}$} & \multicolumn{2}{|l|}{ Univariate analysis } & \multicolumn{2}{|c|}{ Multivariate analysis } \\
\hline & & HR $(95 \%$ Cl) & $P$ value & HR $(95 \% \mathrm{Cl})$ & $P$ value \\
\hline Age $\geq 75$ years & 215 & 3.18 (2.41 to 4.19$)$ & $<0.001^{*}$ & 2.35 (1.76 to 3.15$)$ & $<0.001^{*}$ \\
\hline Male & 135 & 0.76 (0.60 to 0.97$)$ & $0.024^{*}$ & $1.03(0.81$ to 1.31$)$ & 0.788 \\
\hline Hypertension & 212 & 1.84 (1.40 to 2.42$)$ & $<0.001^{*}$ & 1.34 (1.01 to 1.77$)$ & $0.044^{*}$ \\
\hline Diabetes mellitus & 133 & 1.54 (1.22 to 1.95$)$ & $<0.001 *$ & $1.17(0.92$ to 1.50$)$ & 0.208 \\
\hline Smoker & 119 & 1.04 (0.82 to 1.32 ) & 0.739 & & \\
\hline Heart failure & 58 & 2.44 (1.83 to 3.26$)$ & $<0.001^{*}$ & 1.49 (1.10 to 2.01$)$ & $0.009^{*}$ \\
\hline Peripheral arterial disease & 24 & 2.23 (1.47 to 3.39$)$ & $<0.001^{*}$ & 1.20 (0.78 to 1.85$)$ & 0.413 \\
\hline Prior coronary revascularisation & 37 & 0.91 (0.65 to 1.29 ) & 0.603 & & \\
\hline Prior stroke & 79 & 2.09 (1.61 to 2.71$)$ & $<0.001 *$ & 1.55 (1.18 to 2.03$)$ & $0.001^{*}$ \\
\hline Prior $\mathrm{CABG}$ & 15 & $0.68(0.41$ to 1.15$)$ & 0.152 & & \\
\hline $\mathrm{eGFR}<60 \mathrm{~mL} / \mathrm{min}$ & 208 & 2.98 (2.28 to 3.90$)$ & $<0.001^{*}$ & 1.95 (1.47 to 2.59$)$ & $<0.001^{*}$ \\
\hline \multicolumn{6}{|l|}{ TRS $2^{\circ} \mathrm{P}$ score } \\
\hline 0 & 2 & Reference & & Reference & \\
\hline 1 & 12 & $1.88(0.42$ to 8.40$)$ & 0.409 & & \\
\hline 2 & 38 & 4.60 (1.11 to 19.07$)$ & $0.035^{*}$ & & \\
\hline 3 & 70 & 8.44 (2.07 to 34.43$)$ & $0.003^{*}$ & & \\
\hline 4 & 71 & 11.10 (2.72 to 45.23$)$ & 0.001 * & & \\
\hline 5 & 54 & 15.98 (3.90 to 65.58$)$ & $<0.001^{*}$ & & \\
\hline $6-9$ & 34 & 20.18 (4.85 to 84.05$)$ & $<0.001^{*}$ & & \\
\hline
\end{tabular}

CABG, coronary artery bypass grafting; eGFR, estimated glomerular filtration rate;TRS 2 ${ }^{\circ}$, Thrombolysis In Myocardial Infarction Risk Score for Secondary Prevention.

$64.4 \%$ a beta-adrenergic blocker and $55.8 \%$ an angiotensin-converting enzyme inhibitor.

\section{Outcomes}

At a median follow-up of 31 months (IQR: 11.4 to 60.2 months), 281 patients $(31.5 \%)$ developed a primary composite endpoint of CV death, non-fatal MI or non-fatal stroke. On multivariate analysis, age $\geq 75$ years, hypertension, history of heart failure, prior stroke and renal impairment with eGFR $<60 \mathrm{~mL} / \mathrm{min}$ at the index NSTEMI were shown to increase risk of a primary composite endpoint (table 2). With increasing TRS $2^{\circ} \mathrm{P}$ score, there was a progressive increase in incidence of primary composite endpoint (table 3). The annual incidence of primary composite endpoint for patients with TRS $2^{\circ} \mathrm{P}$ score $=0$ was $1.6 \%$, and increased progressively to $47.4 \%$ for those with TRS $2^{\circ} \mathrm{P}$ score $\geq 6$ (HR: $20.18,95 \%$ CI: 4.85 to $84.05, \mathrm{p}<0.001)$. Figure 1 shows a Kaplan-Meier analysis of composite endpoint among patients stratified according to the TRS $2^{\circ} \mathrm{P}$ score (Log-rank: $\left.121.8, \mathrm{p}<0.0001\right)$.

One hundred and ninety-six patients suffered from CV death during the study period. Ninety-two patients died of a fatal MI,

Table 3 Annual risk of composite events (cardiovascular death, non-fatal myocardial infarction and non-fatal stroke)

\begin{tabular}{lcl}
\hline & $\begin{array}{l}\text { Number of patients } \\
\text { (percentages) }\end{array}$ & $\begin{array}{l}\text { Annual risk of composite } \\
\text { event }\end{array}$ \\
\hline TRS 2 ${ }^{\circ}$ P score & & P value for trend $<0.001$ \\
\hline 0 & $43(4.8)$ & $1.6 \%$ \\
\hline 1 & $130(14.6)$ & $2.9 \%$ \\
\hline 2 & $179(20.1)$ & $7.2 \%$ \\
3 & $206(23.1)$ & $14.8 \%$ \\
4 & $168(18.9)$ & $20.1 \%$ \\
\hline 5 & $106(11.9)$ & $33.7 \%$ \\
\hline $6-9$ & $59(6.6)$ & $47.4 \%$ \\
\hline
\end{tabular}

TRS $2^{\circ}$ P, Thrombolysis In Myocardial Infarction Risk Score for Secondary Prevention.
71 died of heart failure, 24 died of acute fatal stroke, 4 died of peripheral arterial disease, 4 died of valvular heart disease and 1 died of sudden cardiac death. Similar to the primary composite endpoint, TRS $2^{\circ} \mathrm{P}$ score, age $\geq 75$ years, hypertension, history of heart failure, prior ischaemic stroke and renal impairment with eGFR $<60 \mathrm{~mL} / \mathrm{min}$ at the index NSTEMI were associated with increasing risk of CV death (table 4, figure 2, Log-rank: 102.8, $\mathrm{p}<0.0001$ ). Concerning MI, there were 186 recurrent (fatal and non-fatal) MIs and among these, 92 MIs were fatal. TRS $2^{\circ} \mathrm{P}$ score together with age $\geq 75$ years and diabetes mellitus at the index NSTEMI was associated with increasing risk of non-fatal MI. Incremental increase in TRS $2^{\circ} \mathrm{P}$ score was associated with a progressively higher incidence of non-fatal MIs (table 5, figure 3, Log-rank: 97.3, p<0.001). In contrast, Cox proportional hazards

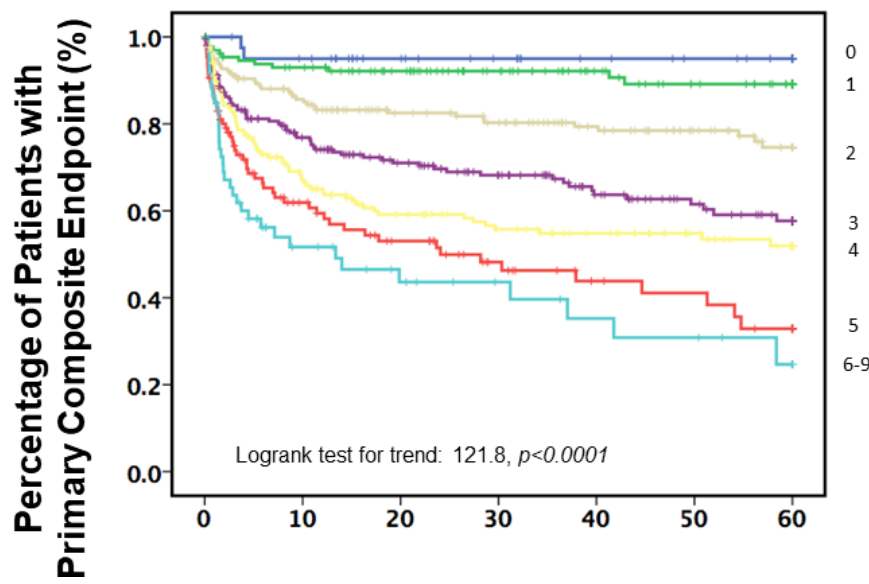

Figure 1 Kaplan-Meier estimates of primary composite endpoint-free survival in post-myocardial infarction patients stratified according the TRP $2^{\circ} \mathrm{P}$ score. TRS $2^{\circ} \mathrm{P}$, Thrombolysis In Myocardial Infarction Risk Score for Secondary Prevention. 
Table 4 Associations between baseline factors and cardiovascular death

\begin{tabular}{|c|c|c|c|c|c|}
\hline & \multirow{2}{*}{$\begin{array}{l}\text { Number of } \\
\text { cardiovascular deaths }\end{array}$} & \multicolumn{2}{|l|}{ Univariate analysis } & \multicolumn{2}{|c|}{ Multivariate analysis } \\
\hline & & $\mathrm{HR}(95 \% \mathrm{Cl})$ & $P$ value & HR $(95 \% \mathrm{Cl})$ & $P$ value \\
\hline Age $\geq 75$ years & 161 & 4.42 (3.07 to 6.37$)$ & $<0.001^{*}$ & 3.17 (2.18 to 4.63$)$ & $<0.001^{*}$ \\
\hline Male & 96 & 0.83 (0.62 to 1.09 ) & 0.18 & & \\
\hline Hypertension & 149 & 1.87 (1.35 to 2.60$)$ & $<0.001^{*}$ & 1.39 (1.0 to 1.94$)$ & $0.049^{*}$ \\
\hline Diabetes mellitus & 86 & 1.27 (0.96 to 1.69$)$ & 0.094 & & \\
\hline Smoker & 83 & 1.05 (0.79 to 1.40$)$ & 0.726 & & \\
\hline Heart failure & 44 & 2.64 (1.89 to 3.70$)$ & $<0.001^{*}$ & 1.57 (1.11 to 2.22$)$ & $0.011^{*}$ \\
\hline Peripheral arterial disease & 18 & 2.29 (1.41 to 3.73$)$ & $0.001 *$ & 1.17 (0.71 to 1.93$)$ & 0.545 \\
\hline Prior coronary revascularisation & 23 & 0.81 (0.52 to 1.25$)$ & 0.34 & & \\
\hline Prior stroke & 60 & 2.34 (1.73 to 3.18$)$ & $<0.001^{*}$ & 1.75 (1.28 to 2.40$)$ & $<0.001^{*}$ \\
\hline Prior $C A B G$ & 11 & 0.75 (0.41 to 1.38$)$ & 0.35 & & \\
\hline $\mathrm{eGFR}<60 \mathrm{~mL} / \mathrm{min}$ & 151 & 3.38 (2.42 to 4.71$)$ & $<0.001^{*}$ & 2.08 (1.47 to 2.95$)$ & $<0.001$ * \\
\hline \multicolumn{6}{|l|}{ TRS $2^{\circ} \mathrm{P}$ score } \\
\hline 0 & 1 & Reference & & & \\
\hline 1 & 6 & $1.80(0.22$ to 14.98$)$ & 0.585 & & \\
\hline 2 & 24 & $5.52(0.75$ to 40.80$)$ & 0.094 & & \\
\hline 3 & 49 & 11.23 (1.55 to 81.32$)$ & $0.017^{*}$ & & \\
\hline 4 & 49 & 13.84 (1.91 to 100.23$)$ & $0.009^{*}$ & & \\
\hline 5 & 41 & 22.08 (3.04 to 160.55$)$ & $0.002^{*}$ & & \\
\hline $6-9$ & 26 & 29.81 (4.04 to 219.81 ) & $0.001^{*}$ & & \\
\hline
\end{tabular}

${ }^{*} p<0.05$; multivariate analysis including individual parameters with $p$-value $<0.05$ in univariate analysis except the TRS $2{ }^{\circ} \mathrm{P}$ score.

CABG, coronary artery bypass grafting; eGFR, estimated glomerular filtration rate;TRS $2^{\circ} \mathrm{P}$, Thrombolysis In Myocardial Infarction Risk Score for Secondary Prevention.

regression analysis showed there was no factor associated with risk of non-fatal ischaemic stroke (figure 4).

\section{DISCUSSION}

In this study, we demonstrated the validity of using TRS $2^{\circ} \mathrm{P}$ score to predict long-term risk of CV events in a real-world cohort of NSTEMI patients. More importantly, the incremental increase in risk is proportional to the score itself which makes it a powerful tool to risk-stratify patients for surveillance and treatment. In past decades, more attention was put on acute reperfusion for STEMI while NSTEMI was regarded as less urgent and malignant. However, in recent years, more evidence have shown NSTEMI actually has a similar if not worse long-term prognosis than STEMI. Besides, NSTEMI patients tend to be older and have more comorbidities. $^{5-823}$ In our NSTEMI cohort, 281 patients $(31.5 \%)$ developed a recurrent event (CV death, non-fatal MI or non-fatal

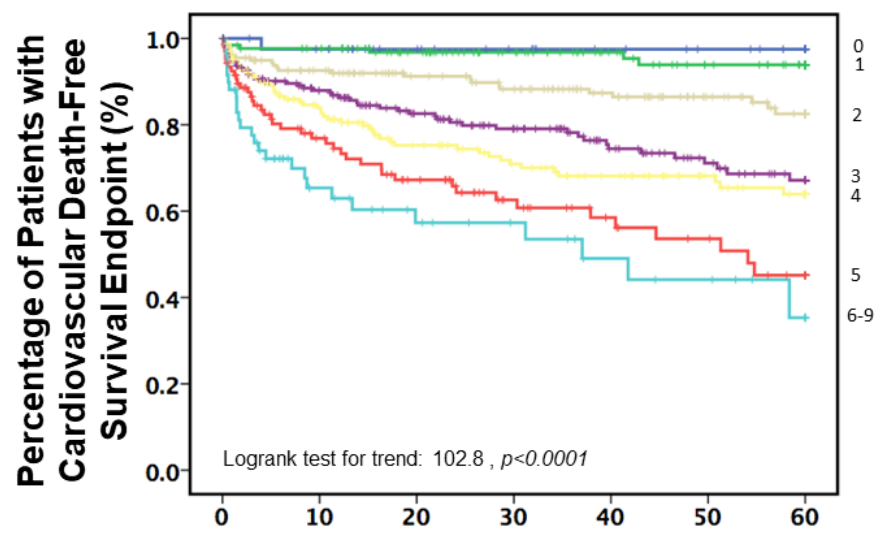

Figure 2 Kaplan-Meier estimates of cardiovascular death-free survival in post-myocardial infarction patients stratified according the TRP $2^{\circ} \mathrm{P}$ score. TRS $2^{\circ} \mathrm{P}$, Thrombolysis In Myocardial Infarction Risk Score for Secondary Prevention. stroke) at a median follow-up of 31 months which corresponded to an annual incidence of $13.3 \%$. Besides, the incidence of NSTEMI is higher than STEMI in most populations which makes NSTEMI a heavy burden on healthcare systems. ${ }^{24}$

Contemporary NSTEMI management emphasises on early invasive revascularisation, potent anti-thrombotics and risk factors control. ${ }^{2}$ International guidelines recommend ischaemic risk assessment in acute phase such as the Global Registry of Acute Coronary Events risk score and TIMI risk score to risk-stratify patients for site of care, timing of coronary angiography and antithrombotic regime. ${ }^{2}$ Once the patients survive to discharge, aggressive treatment is also indicated for secondary prevention in view of the high long-term residual CV risk. Potential effective treatment include potent and prolonged antiplatelet agents ${ }^{29}$; anticoagulants ${ }^{25}{ }^{26}$; lipid lowering therapies including statin, ${ }^{3}$ ezetimibe, ${ }^{10}{ }^{11}$ PCSK9 inhibitors, ${ }^{12}$ icosapent ethyl ${ }^{27}$ and anti-inflammatory agents such as anti-interleukin- $1 \beta .^{28}$ The list is exhaustive and there are treatments under research. Nevertheless, these agents are not without adverse effects and many of them are prohibitively expensive for which cost-effectiveness becomes an issue from healthcare management point of view. Consequently, risk-stratification of NSTEMI patients to select patients who derive more benefit will be of utmost importance. The TRS $2^{\circ} \mathrm{P}$ score was validated in the TIMI 50 trial, ${ }^{17}$ IMPROVE-IT trial ${ }^{18}$ and our real-world cohort to predict occurrence of long-term CV events. Indeed, in the TIMI 50 trial, ${ }^{17}$ a gradient of absolute risk reduction with vorapaxar across the TRS $2^{\circ} \mathrm{P}$ score was clearly shown. The absolute risk reductions in terms of CV death, MI or ischaemic stroke, were $0.1 \%, 2.1 \%$ and $3.2 \%$ over the 3 -year study period for patients with a TRS $2{ }^{\circ} \mathrm{P}$ score of $0,1-2$ and $\geq 3$, respectively. The much greater absolute risk reduction in patients with high TRS $2^{\circ} \mathrm{P}$ score outweighs the accompanying bleeding from vorapaxar, thereby justifying the use of such treatment(20). Similarly, in IMPROVE-IT trial, ${ }^{18}$ patients with a TRS $2^{\circ} \mathrm{P}$ score $>3$ derived a $6.6 \%$ absolute reduction in risk of CV death, major coronary event or stroke from the addition of ezetimibe to simvastatin therapy, while patients with the lowest risk 
Table 5 Associations between baseline factors and non-fatal AMI

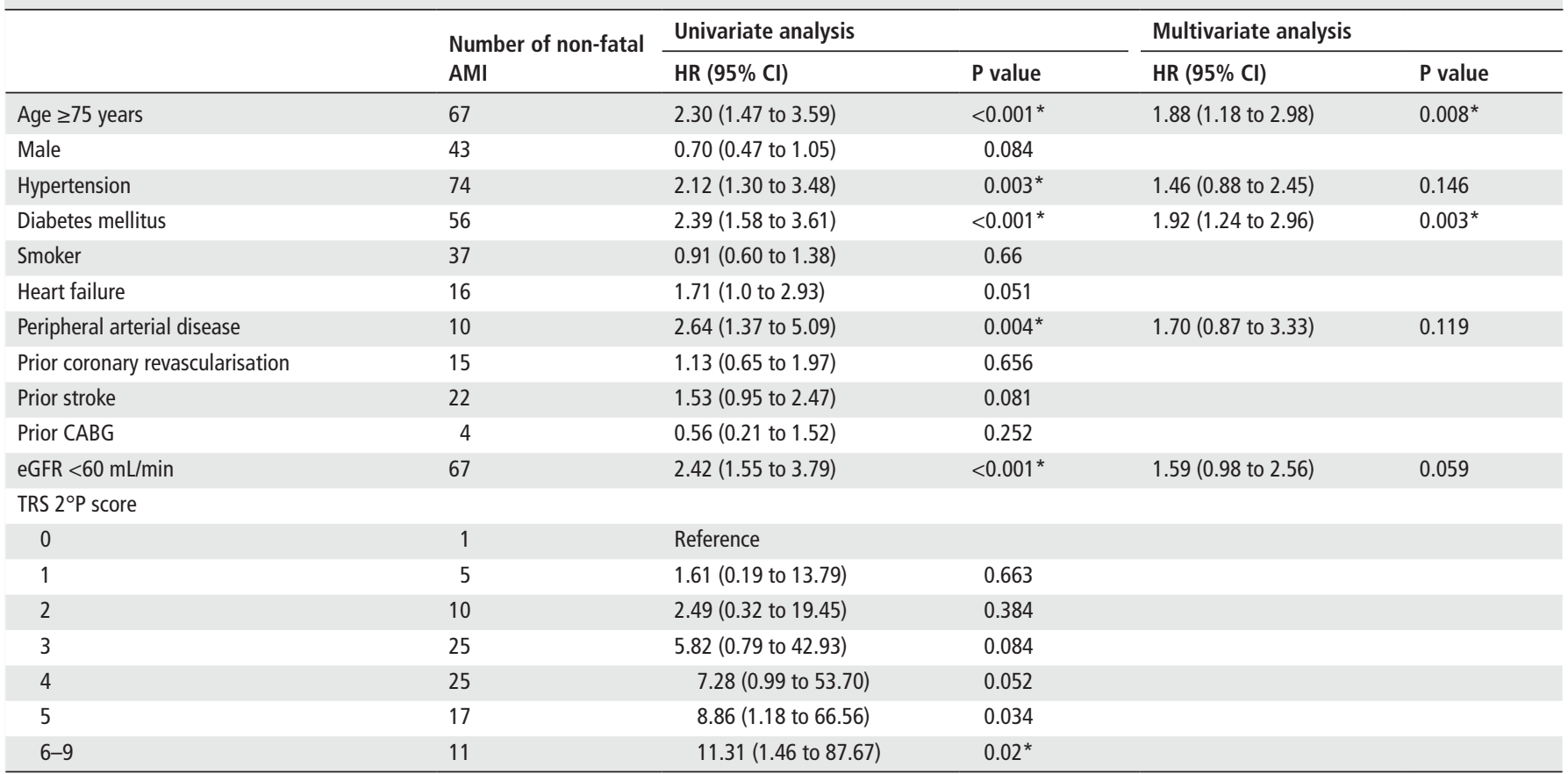

${ }^{*} \mathrm{p}<0.05$; multivariate analysis including individual parameters with $\mathrm{p}$-value $<0.05$ in univariate analysis except the TRS $2^{\circ} \mathrm{P}$ score.

AMI, acute myocardial infection; $C A B G$, coronary artery bypass grafting; eGFR, estimated glomerular filtration rate;TRS $2^{\circ}$ P, Thrombolysis In Myocardial Infarction Risk Score for Secondary Prevention.

(TRS $2^{\circ} \mathrm{P}$ score: $\left.0-1\right)$ had no reduction in events from addition of ezetimibe over a study period of 7 years. These data provide insight into the use of TRS $2^{\circ} \mathrm{P}$ score to personalise treatment to attain maximum benefit while minimise potential side effects and cost. Therefore, it seems that TRS $2^{\circ} \mathrm{P}$ score is a readily available clinical risk score that can be effective for treatment guidance similar to $\mathrm{CHA}_{2} \mathrm{DS}_{2}$-VASc score for thromboembolic risk stratification in the setting of atrial fibrillation. ${ }^{29-34}$

\section{Limitations}

This study is a single-centre observational registry with relatively small sample size. In fact, the negative impact of TRS $2^{\circ} \mathrm{P}$ score on ischaemic stroke is likely due to low number of stroke events in the cohort. Besides, the analysed period is from 2004 to 2011

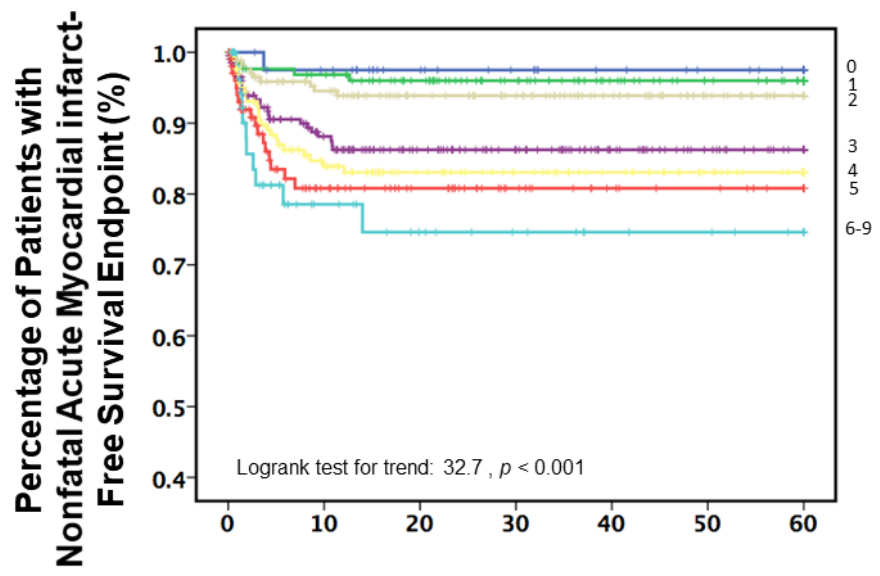

Figure 3 Kaplan-Meier estimates of non-fatal myocardial infarctionfree survival in post-myocardial infarction patients stratified according the TRP $2^{\circ} \mathrm{P}$ score. TRS $2^{\circ} \mathrm{P}$, Thrombolysis In Myocardial Infarction Risk Score for Secondary Prevention. during which the treatment standard may not be comparable to the present day. In our cohort, only $25.7 \%$ of acute NSTEMI patients received in-patient revascularisation and the use of guideline-directed medications was also not acceptable according to current standard. Nevertheless, it may represent a typical pattern of realworld clinical practice. In addition, as for all registry studies, patient inclusion is always subject to bias. We have tried to review hospital records, laboratory and imaging results carefully to ascertain the diagnosis but potential confounding still cannot be excluded.

\section{CONCLUSION}

In post-NSTEMI patients, a simple clinical TRS $2^{\circ} \mathrm{P}$ score can potentially predict medium to long-term future $\mathrm{CV}$ events in a realworld setting. More studies are required to assess whether a TRS

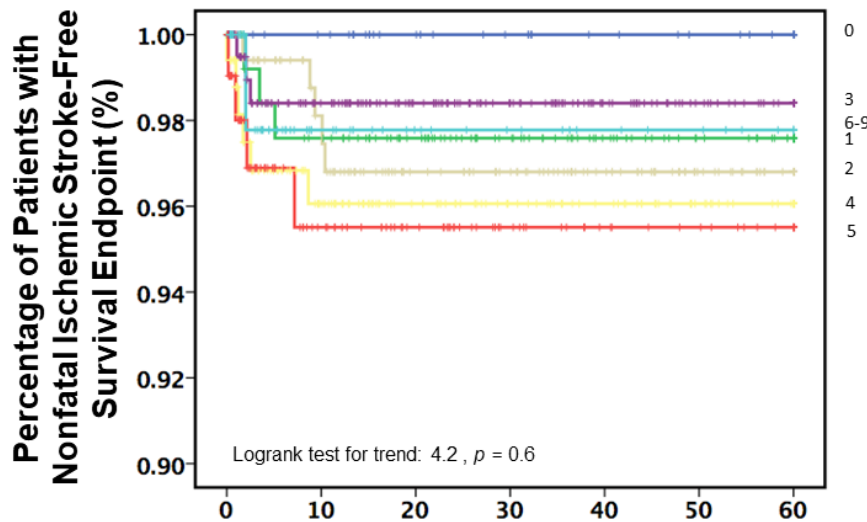

Figure 4 Kaplan-Meier estimates of non-fatal ischaemic stroke-free survival in post-myocardial infarction patients stratified according the TRP $2^{\circ} \mathrm{P}$ score. TRS $2^{\circ} \mathrm{P}$, Thrombolysis In Myocardial Infarction Risk Score for Secondary Prevention. 
$2^{\circ} \mathrm{P}$ score-directed therapy approach can improve patient outcome in a risk/cost-effective way.

\section{Main messages}

TRS $2^{\circ} \mathrm{P}$ score predicted future cardiovascular risk in a realworld cohort of NSTEMI patients incrementally.

- TRS $2^{\circ} \mathrm{P}$ score-directed approach selects patients who will benefit most from aggressive secondary prevention therapies which potentially minimises treatment side effects and cost.

\section{Current research questions}

- Further studies are required to evaluate the clinical value and cost-effectiveness of TRS $2^{\circ} \mathrm{P}$ score-directed therapy approach.

\section{What is already known on the subject}

- Patients survived Non-ST elevation myocardial infarction (NSTEMI) are at heightened risk of future cardiovascular events. Aggressive secondary preventive measures are important.

- The TIMI Risk Score for Secondary Prevention (TRS $\left.2^{\circ} \mathrm{P}\right)$ score was developed to predict recurrent cardiovascular risks in post-NSTEMI patients and has been validated in randomised clinical trials.

Contributors DH, YYC, YQF, NT, JYC, MXW, XS, HY, DS, CWS and CCT contributed to the conceptual design of the study. All authors contributed to the conduction of study and data collection. DH, YYC, YTW, SYY, CWS and CCT contributed to the interpretation of data. DH, YYC, CWS and CCT contributed to write-up and submission of the study. All authors reviewed and agreed with the content of the article.

Funding This research received no specific grant from any funding agency in the public, commercial or not-for-profit sectors.

Competing interests None declared.

Patient consent for publication Not required.

Ethics approval The study protocol was approved by the local Institutional Review Board.

Provenance and peer review Not commissioned; externally peer reviewed.

Data availability statement Data may be obtained from a third party and are not publicly available.

\section{REFERENCES}

1 Stone NJ, Robinson JG, Lichtenstein AH, et al. 2013 ACC/AHA guideline on the treatment of blood cholesterol to reduce atherosclerotic cardiovascular risk in adults. Circulation 2014;129(25 suppl 2):S1-S45

2 Roffi M, Patrono C, Collet JP, et al. ESC scientific document group. 2015 ESC guidelines for the management of acute coronary syndromes in patients presenting without persistent ST-segment elevation: Task Force for the management of acute coronary syndromes in patients presenting without persistent ST-segment elevation of the European Society of cardiology (ESC). European Heart Journal 2016:37:267-315.

3 Drozda JP, Ferguson TB, Jneid H, et al. 2015 ACC/AHA focused update of secondary prevention lipid performance measures: a report of the American College of Cardiology/American Heart Association Task Force on performance measures. J Am Coll Cardiol 2016:67:558-87.

4 Zhang Q, Zhao D, Xie W, et al. Recent trends in hospitalization for acute myocardial infarction in Beijing: increasing overall burden and a transition from ST-segment elevation to non-ST-segment elevation myocardial infarction in a population-based study. Medicine 2016;95:e2677.

5 Montalescot G, Dallongeville J, Van Belle E, et al. STEMI and NSTEMI: are they so different? 1 year outcomes in acute myocardial infarction as defined by the ESC/ACC definition (the opera registry). European Heart Journal 2007;28:1409-17.
6 Chan MY, Sun JL, Newby LK, et al. Long-term mortality of patients undergoing cardiac catheterization for ST-elevation and non-ST-elevation myocardial infarction. Circulation 2009;119:3110-7.

7 McManus DD, Gore J, Yarzebski J, et al. Recent trends in the incidence, treatment and outcomes of patients with STEMI and NSTEMI. The American Journal of Medicine 2011:124:40-7.

8 Darling CE, Fisher KA, McManus DD, et al. Survival after hospital discharge for ST-segment elevation and non-ST-segment elevation acute myocardial infarction: a population-based study. Clinical epidemiology 2013;5:229-36.

9 Bonaca MP, Bhatt DL, Cohen M, et al. Long-term use of ticagrelor in patients with prior myocardial infarction. New England Journal of Medicine 2015;372:1791-800

10 Cannon CP, Blazing MA, Giugliano RP, et al. Ezetimibe added to statin therapy after acute coronary syndromes. New England Journal of Medicine 2015;372:2387-97.

11 Lloyd-Jones DM, Morris PB, Ballantyne CM, et al. 2017 Focused update of the 2016 ACC expert consensus decision pathway on the role of non-statin therapies for Idlcholesterol lowering in the management of atherosclerotic cardiovascular disease risk: a report of the american college of cardiology task force on expert consensus decision pathways. J Am Coll Cardiol 2017;70:1785-822.

12 Sabatine MS, Giugliano RP, Keech AC, et al. Evolocumab and clinical outcomes in patients with cardiovascular disease. New England Journal of Medicine 2017;376:1713-22

13 Fonarow GC, Keech AC, Pedersen TR, et al. Cost-effectiveness of evolocumab therapy for reducing cardiovascular events in patients with atherosclerotic cardiovascular disease. JAMA Cardiology 2017:2:1069-78.

14 Villa G, Lothgren M, Kutikova L, et al. Cost-effectiveness of evolocumab in patients with high cardiovascular risk in Spain. Clinical Therapeutics 2017;39:771-86.

15 Gandra SR, Villa G, Fonarow GC, et al. Cost-effectiveness of LDL-C lowering with evolocumab in patients with high cardiovascular risk in the United States. Clinical Cardiology 2016;39:313-20

16 Morrow DA, Braunwald E, Bonaca MP, et al. Vorapaxar in the secondary prevention of atherothrombotic events. New England Journal of Medicine 2012;366:1404-13.

17 Bohula EA, Bonaca MP, Braunwald E, et al. Atherothrombotic risk stratification and the efficacy and safety of vorapaxar in patients with stable ischemic heart disease and previous myocardial infarction. Circulation 2016;134:304-13.

18 Bohula EA, Morrow DA, Giugliano RP, et al. Atherothrombotic risk stratification and ezetimibe for secondary prevention. J Am Coll Cardiol 2017;69:911-21.

19 Wong KL, Wong YTA, Yung SYA, et al. A single centre retrospective cohort study to evaluate the association between implementation of an acute myocardial infarction clinical pathway and clinical outcomes. International Journal of Cardiology 2015;182:82-4.

20 Huang $D$, Cheng Y-Y, Wong Y-TA, et al. Thrombolysis in myocardial infarction risk score for secondary prevention of recurrent cardiovascular events in A real-world cohort of post-acute myocardial infarction patients. Circ J 2019;83:809-17.

21 Greenberg H, Case RB, Moss AJ, et al. Analysis of mortality events in the Multicenter Automatic Defibrillator Implantation Trial (MADIT-II). Journal of the American College of Cardiology 2004;43:1459-65.

22 Hinkle LE, Thaler HT. Clinical classification of cardiac deaths. Circulation 1982:65:457-64

23 Allen LA, O'Donnell CJ, Camargo CA, et al. Comparison of long-term mortality across the spectrum of acute coronary syndromes. Am Heart J 2006;151:1065-71.

24 Mozaffarian D, Benjamin EJ, AS G, et al. 3rd, Moy CS, Muntner P, Mussolino me, Nasir K, Neumar Rw, Nichol G, Palaniappan L, Pandey DK, Reeves MJ, Rodriguez CJ, Sorlie PD, Stein J, Towfighi a, Turan Tn, Virani SS, Willey JZ, Woo D, Yeh Rw, Turner MB. Heart disease and stroke statistics-2015 update: a report from the American Heart Association. Circulation 2015;131:e29-322.

25 Mega JL, Braunwald E, Wiviott SD, et al. Rivaroxaban in patients with a recent acute coronary syndrome. New England Journal of Medicine 2012;366:9-19.

26 Eikelboom JW, Connolly SJ, Bosch J, et al. Rivaroxaban with or without aspirin in stable cardiovascular disease. N Eng/ J Med Overseas Ed 2017:377:1319-30.

27 Bhatt DL, Steg PG, Miller M, et al. Cardiovascular risk reduction with Icosapent ethyl for hypertriglyceridemia. N Engl J Med 2019;380:11-22.

28 Ridker PM, Everett BM, Thuren T, et al. Antiinflammatory therapy with canakinumab for atherosclerotic disease. N Engl J Med Overseas Ed 2017:377:1119-31.

29 Chiang C-E, Okumura K, Zhang S, et al. 2017 consensus of the Asia Pacific heart rhythm Society on stroke prevention in atrial fibrillation. J Arrhythm 2017;33:345-67.

30 Kirchhof $\mathrm{P}$, Benussi S, Kotecha D, et al. 2016 ESC guidelines for the management of atrial fibrillation developed in collaboration with EACTS. Eur Heart $\lrcorner$ 2016;37:2893-962.

31 Chan P-H, Lau C-P, Tse H-F, et al. Cha 2 Ds 2 -VASc recalibration with an additional age category (50-64 years) enhances stroke risk stratification in Chinese patients with atrial fibrillation. Can J Cardio/ 2016;32:1381-7.

32 Chan P-H, Huang D, Lau C-P, et al. Net clinical benefit of dabigatran over warfarin in patients with atrial fibrillation stratified by CHA2DS2-VASC and time in therapeutic range. Canadian Journal of Cardiology 2016;32:1247.e15-1247.e21.

33 Siu C-W, Tse H-F. Net clinical benefit of warfarin therapy in elderly Chinese patients with atrial fibrillation. Circ Arrhythm Electrophysiol 2014;7:300-6.

34 Siu C-W, Lip GYH, Lam K-F, et al. Risk of stroke and intracranial hemorrhage in 9727 Chinese with atrial fibrillation in Hong Kong. Heart Rhythm 2014;11:1401-8. 